\title{
Researchers unite in demand for funding
}

Cite as: CMAJ 2017 June 19;189:E847. doi: 10.1503/cmaj.1095441

M ore than 200 scientists gathered in Toronto to call for the federal government to increase scientific research spending and fully adopt the new report from Canada's Fundamental Science Review panel. The scientists met May 31 to refine strategies aimed at prodding Ottawa to increase research spending after a decade-long federal science budget freeze. Many speakers warned that Canadian science is rapidly withering because of under-investment.

The summit opened with a presentation from Dr. David Naylor, chair of Canada's Fundamental Science Review panel, which tabled a report in April recommending $\$ 1.3$ billion in additional federal science spending over four years, to bring total annual expenditure to $\$ 4.8$ billion by 2022.

Naylor warned that, without increased funding, Canada risks a "stall-out relative to peer nations." The decline in spending, he said, is "deeply worrying" and risky, particularly because of the subsequent loss of earlystage researchers. "This is a leadership moment. Canada has fallen behind."

Naylor also emphasized the need for stronger, more accountable mechanisms to govern federal science decisions. His report calls for an independent National Advisory Council on Research and Innovation, a suggestion that was endorsed at the summit by the Ottawa-based Evidence for Democracy.
Much of the summit was devoted to brainstorming and debating strategies to encourage the government to increase funding in next year's budget.

"We don't want to argue that researchers are entitled to support, which comes across as entitled," said University of Ottawa biologist Jeremy Kerr. "We've got to be able to describe the benefits to Canadians."

"We've found that what resonates with politicians is local job creation," added David Hill, scientific director of Lawson Research Institute in London, England. "We should strongly emphasise that investment in science does that."

The summit concluded with a unanimous vote endorsing the recommendations of the Naylor report.
"We need to tell the government this is a very good report which we fully support," said Jim Woodgett, cochair of the summit and director of research at the Lunenfeld-Tanenbaum Research Institute.

"The message is that we want the government to implement the Naylor Report now, and implement it fully," Mehrdad Hariri, president and CEO of the Canadian Science Policy Centre, said.

A message to the gathering from the federal Minister of Science, Kirsty Duncan, emphasized the need to balance science spending with the needs of "marginalized and disadvantaged people."

Paul Webster, Toronto, Ont.

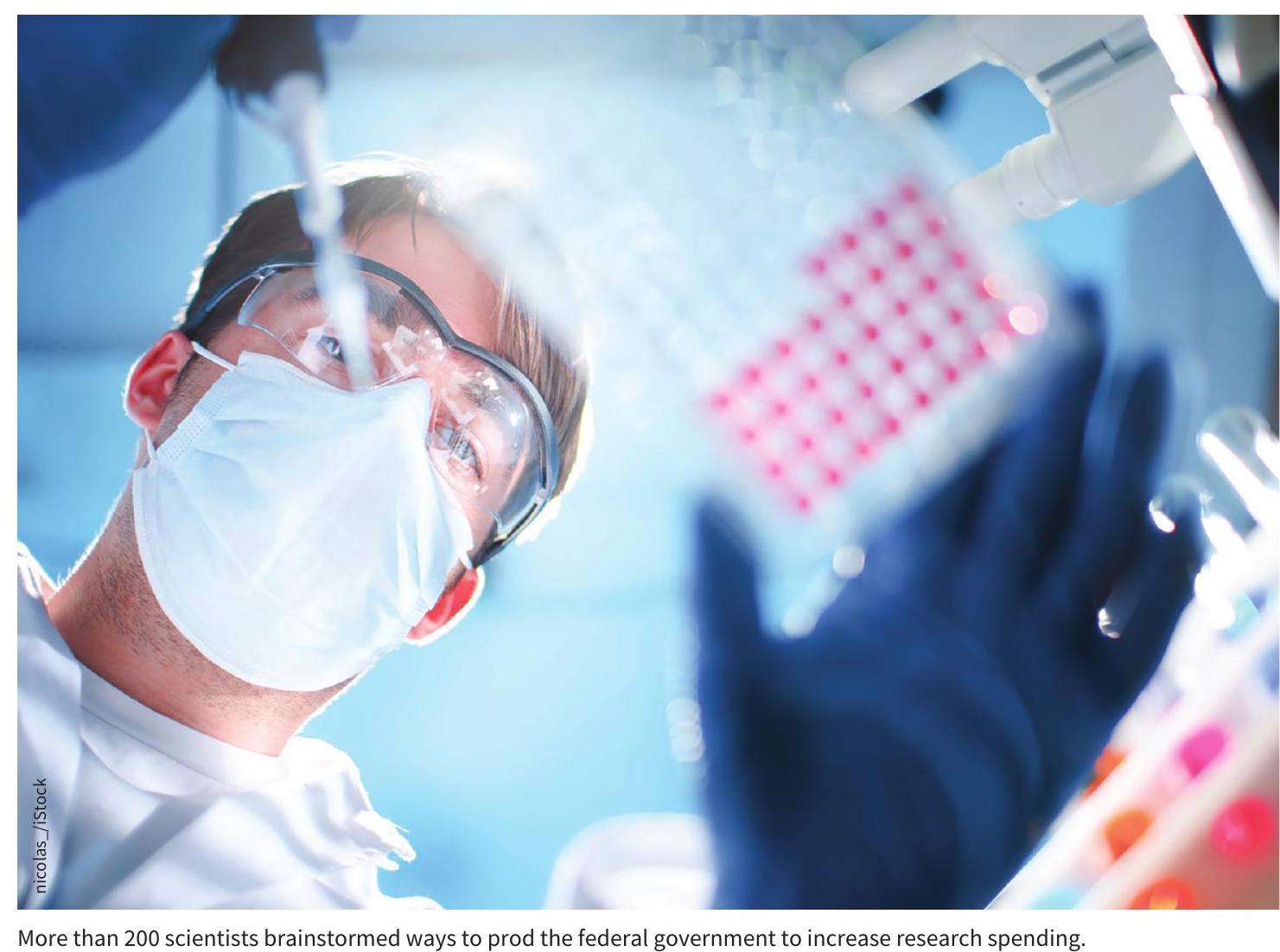

